\title{
UMA REFLEXÃO SOBRE A ETNOMATEMÁTICA DO PEDREIRO E A MATEMÁTICA ESCOLAR
}

\section{ARTIGO ORIGINAL}

SCHWANTES, Vilson ${ }^{1}$

XAVIER, Márcio Pizzete ${ }^{2}$

SCHWANTES, Eloísa Bernardete Finkler ${ }^{3}$

SCHWANTES, Daniel ${ }^{4}$

${ }^{1}$ Mestre em Educação nas Ciências - Matemática, pela UNIJUI - RS. Graduação e Especialização em Ciências e Matemática. Prof. Assistente do CCA - Centro de Ciências Agrárias, Campus de Marechal Cândido Rondon, UNIOESTE, PR - Brasil.

2 Mestrando em Desenvolvimento Rural Sustentável-UNIOESTE, Especialista Em Matemática, Física-UNIPAR, Gestão De Pessoas E Educação Especial com Ênfase Na Deficiência Múltipla-UNIASSELVI, Graduado Em Matemática Com Ênfase Em Física-UNIPAR.

${ }^{3}$ Especialização em Ensino de Ciências Exatas - Matemática, Física e Química. UNIOESTE - Universidade Estadual do Oeste do Paraná. Graduação:Ciências e Matemática. UNIJUI, RS. Professora da Rede Estadual de Ensino do Estado do Paraná.

${ }^{4}$ Professor da área de Proteção de Plantas e Saúde Humana da Pontifícia Universidad Católica de Chile, Departamento de Ciências Vegetales, ocupa um cargo interdisciplinar compartilhado entre a Facultad de Agronomía e Ingeniería Forestal (FAIF), Facultad de Medicina y Facultad de Química. Professor pesquisador associado ao Grupo de Estudos em Solos e Meio Ambiente (GESOMA - UNIOESTE). Mestre em Agronomia pela UNIOESTE, Doutor em Agronomia pela UNIOESTE (20132016) - Período Sanduíche (Bolsista CAPES) pela Universidade de Lisboa, no Instituto Superior de Agronomia (ULisboa). 
JUNIOR, Affonso Celso Gonçalves ${ }^{5}$

KRACKE, Elisa ${ }^{6}$

JUNIOR, Élio Conradi ${ }^{7}$

SCHWANTES, Vilson. Et al. Uma reflexão sobre a etnomatemática do pedreiro e a matemática escolar. Revista Científica Multidisciplinar Núcleo do Conhecimento. Ano 04, Ed. 07, Vol. 14, pp. 87-106. Julho de 2019. ISSN: 2448-0959

\section{RESUMO}

Este artigo reflete sobre etnomatemática, analisa entrevistas com um grupo de pedreiros e vendedores de material de construção dos municípios de Mercedes e Marechal Cândido Rondon, PR. Busca conhecer os conhecimentos matemáticos utilizados por estes trabalhadores no exercício de suas profissões e sua possível relação com o ensino da matemática escolar. Nos relatos dos participantes transparece que estes conhecimentos estão intimamente ligados ao meio

${ }^{5}$ Bolsista Produtividade em Pesquisa nível $1 \mathrm{C}$ pelo CNPq na área de Ciências Ambientais com três Pós-doutorados, UEM-PR (Brasil), Universidade de Santiago de Compostela (Espanha), UFG-GO (Brasil). Atualmente é Professor Associado da UNIOESTE-PR e atua como docente e pesquisador do Centro de Ciências Agrárias, ministrando aulas na área de Química. Docente no Programa de Mestrado em Ciências Agrárias da UEM. Atualmente é consultor ad hoc do CNPq, CAPES e Fundação Araucária. Atua como consultor ambiental voluntário junto ao MP-SP e CONAMA-DF.

${ }^{6}$ Graduanda em Agronomia - UNIOESTE - Universidade Estadual do Oeste do Paraná -Graduanda de Administração - Unip - Universidade Paulista.

${ }^{7}$ Mestrando em Agronomia (Produção Vegetal) pela Universidade Estadual do Oeste do Paraná (UNIOESTE). Engenheiro Agrônomo formado pela UNIOESTE (20142018), atua como pesquisador associado ao Grupo de Estudos em Solos e Meio Ambiente (GESOMA - UNIOESTE). 
sociocultural, denotando uma concepção de que a escola é um local privilegiado onde se aprende de forma organizada e sistematizada os conhecimentos matemáticos necessários para a vida profissional. Fica evidenciado que existem desafios a serem superados pela escola para sua efetiva consolidação, de modo que a prática pedagógica do ensino escolar tenha conexões com o mundo sócio-cultural do aluno.

Palavras-Chave: Perspectiva etnomatemática, educação matemática, conhecimentos matemáticos, cotidiano da sala de aula.

\section{INTRODUÇÃO}

O ensino da matemática nas escolas brasileiras, ao longo das últimas décadas, tem se mostrado predominantemente tradicional, sem grandes mudanças pedagógicas, salvo algumas poucas exceções. Dentro desta perspectiva e realidade percebe-se que pouco se utiliza dos sabres prévios dos educandos, e menos ainda se faz relações dos conceitos matemáticos ensinados com a vida dos alunos fora do ambiente escolar. Neste cenário ainda é comum ouvirmos no ambiente escolar expressões como: "professor onde vou usar isso na minha vida?".

Segundo Santos (2016):

A falta de contextualização no ensino da matemática pode acarretar no desestímulo pela disciplina, ressuscitando os métodos tradicionais que conceituam a matemática como uma ciência que trouxesse todas as coisas prontas, como se fosse um conhecimento pronto e acabado. (p. 5)

Em muitas escolas brasileiras, com certa frequência ainda se ouve dizer que o ensino de matemática se encontra distante e descontextualizado da realidade vivida pelos alunos e cidadãos. Para Demo (1996), a construção do conhecimento começa a partir dos saberes incorporados por cada indivíduo na sua vivência sociocultural. Para o autor "todos falam, se comunicam, usam um vocabulário básico, manejam conceitos 
dentro do senso comum, possuem referências da realidade em que estão inseridos" (p.32).

Embora ainda estejamos vivenciando situações deste tipo em nossas escolas, existe o consenso de que o aluno ao ingressar na escola traga em sua bagagem algum conhecimento, mesmo que seja apenas no âmbito do senso comum. Inclui-se aí o conhecimento matemático gerado no âmbito da família e nos setores da sociedade, o qual é incorporado pelas crianças e é fundamental que a escola o conheça e o considere, construindo na base desses saberes, o conhecimento sistematizado. Para Pompeu e Monteiro (2001), "os alunos aprendem no cotidiano, na sua relação com o mundo" (p.62).

Para Lopes (2014),

"Ideias e situações de natureza matemática estão presentes nas coisas do dia a dia, nas atividades profissionais, nas práticas de distintas culturas, em situações de contagem, medição e cálculo, que são facilmente reconhecidas como Matemáticas". (p.5)

Um ensino com produção de significados sobre o contexto é tão fundamental quanto o relacionamento com o mundo real, mundo abstrato e simbólico. Partindo-se da vivência cultural de cada aluno, da significação que ele traz de sua vivência social e cultural, pode-se avançar e entender outras culturas, os indivíduos e a sociedade. Compartilhamos com D’Ambrósio (1993), ao postular que é fundamental entender que quando a escolarização formal começa, a criança já possui uma etnomatemática que Ihe permite fazer frente às interpretações da matemática sistematizada da escola.

Esta perspectiva, segundo Marques (2001), representa e significa:

Construção de novos saberes, a partir de saberes anteriores; na verdade, uma reconstrução deles, no sentido de desmontagem e recuperação de modo novo. Os saberes de cada interlocutor confidentes, leitores, autores convocados com suas obras, sujeitos de 
práticas sociais a quem ouvi, entrevistei, interpelei - e os meus saberes se fundem e se transformam, reformulam-se. De maneira muito especial, meus saberes anteriores se configuram agora outros. A isso chamamos de aprendizagem. Por que não de pesquisa? (p. 26).

Compartilhamos com Fiorentini (1995) ao realçar que na abordagem etnomatemática, o processo ensino-aprendizagem, tem como ponto de partida a ênfase dada aos problemas que de alguma maneira tem significação para as crianças. Neste sentido, a relação aluno-professor se dá no âmbito da intersubjetividade, onde através do diálogo, interlocução entre sujeitos, troca de experiências, ambos (re)constroem saberes pela problematização (matematização) sobre o senso comum e o saber sistematizado, construindo um novo olhar sobre o contexto.

Embora se tenha claro que a escola precisa trabalhar o conhecimento matemático sistematizado, acreditamos que uma valorização do conhecimento matemático resultante das relações culturais dos alunos possa fazer crescer positivamente e psicologicamente o rendimento das crianças, em oposição a uma iniciação através de técnicas e regras para se chegar a respostas corretas. Esta possibilidade pode ser vislumbrada e concretizada com a adoção, pelos educadores matemáticos, de uma postura etno no ensino, pois de acordo com Pompeu e Monteiro (2001), "A etnomatemática busca uma transformação das atuais relações do homem com o mundo" (p.148).

Para atuar no mundo hoje, faz-se necessária uma nova postura, um novo paradigma, uma revisão teórica que tenha como objetivo central a organização/reformulação/compreensão da base teórica e prática que permeie a ação pedagógica dos educadores (SILVA, 2012, p.174).

Para D'Ambrósio (2001), a etnomatemática pode auxiliar na constituição do professor pesquisador de sua prática, despertando-o a aprender de maneira continuada a ser professor, segundo as atuais necessidades educacionais, transformando a sala aula 
num ambiente de troca de saberes, resgatando conhecimentos histórico-socialmente construídos pela humanidade.

Os projetos pedagógicos escolares carecem de adequação ao novo paradigma educacional, centrado na intersubjetividade e interlocução dos sujeitos atores. Uma abordagem matemática nesta perspectiva transforma a sala aula num ambiente de troca de saberes pela valorização das diferenças individuais, pois o resgate a curiosidade recupera o conhecimento histórico-socialmente construído pelo homem, ao longo da história da humanidade.

Reflexões e discussões sobre o ensino desta disciplina, consiste também em averiguar as expectativas e necessidades sociais da matemática ensinada na escola, segundo as palavras de Demo (1996, p.10), é "sair da postura reprodutiva surrada, marcada principalmente pela aula repetida feita para só repetir".

As novas tendências na Educação e Educação Matemática enfatizam que a arte de aprender a ensinar envolve não só saber o que ensinar e o saber sobre métodos de ensino, mas, sobretudo, envolve um saber sobre a aprendizagem. Referimo-nos à aprendizagem, tanto do professor, acerca do próprio processo e resultados de sua aprendizagem, quanto de um saber do professor em relação à aprendizagem de seus alunos. (SILVA, 2012, p.197).

Assim, ensinar matemática na sala de aula, levando em consideração os saberes prévios e a diversidade cultural dos educandos pode ser uma importante estratégia para um ensino mais significativo e menos tradicional da matemática escolar, gerando mais interesse e participação dos alunos na construção do saber matemático.

Acreditamos que uma postura didática-pedagógica que parte do conhecimento que o aluno já tem de sua vivência cotidiana, proporciona aos educadores uma (re)construção do conhecimento matemático sistematizado, tanto na percepção da existência de várias matemáticas em nosso meio, quanto da busca de um ensino que contemple as expectativas sociais. 


\section{JUSTIFICANDO A PRESENÇA DA MATEMÁTICA NA ATIVIDADE DIÁRIA DO PEDREIRO}

Ao realizarmos em momentos distintos, as sessões de estudo com os pedreiros, procuramos investigar dialogicamente com cada profissional, suas opiniões a respeito de questões matemáticas de caráter geral que permeiam sua labuta diária.

Questionados sobre a utilização da matemática em seu trabalho, os pedreiros foram unânimes em afirmar que ela é fundamental no exercício de sua profissão. Segundo Oscar, "principalmente no começo de uma obra, o fio prumo. Com o fio de prumo fazemos uma matemática não tão complicada como a da escola e sem fórmulas, complementa o pedreiro. O que a gente mais usa é o raciocínio, enfatiza".

Sérgio comenta que usa a matemática "para medir e calcular a quantidade de telhas, tijolos, às vezes metros quadrados. São cálculos de vezes [multiplicação], mais [adição] e de dividir". Alberto também diz usar a matemática "desde o fundamento da construção, para tirar o esquadro, através do Teorema de Pitágoras. No telhado para fazer a porcentagem da queda d'água. Também uso a matemática nas medidas de área" finaliza.

Quando argumentamos que utilizavam uma matemática prática, Oscar foi logo dizendo que no exercício de uma profissão sempre se utiliza uma matemática "mais prática e simples, não se utiliza às fórmulas ensinadas na escola. A gente sempre tenta simplificar os procedimentos. Numa construção a gente vai definindo o tipo de cálculo que vai usar. A gente não perde muito tempo em cima de cálculos complicados, tudo é feito de forma mais simplificada, argumenta".

Instigado a explicitar melhor a matemática que utiliza e que Ihe permite fazer cálculos simplificadamente, Oscar relatou que se trata de "um raciocínio que é praticamente do dia-a-dia do construtor e envolve especialmente medidas. A gente se preocupa com elas durante todo o dia e, precisa-se ficar sempre atento".

Conforme Breda, Lima e Guimarães (2011, p. 15): 
Passei a olhar a proposta da etnomatemática como uma possibilidade de diferenciar o trabalho que o professor desenvolve nas escolas, ou seja, a prática conteudista e sem significado poderá ser substituída por um fazer docente orientado por um novo olhar, que fomente a valorização do contexto sociocultural do educando, seus processos de pensamento e seus modos de entender, explicar e exercer sua prática na sociedade contemporânea [...] um convite para revisitar suas práticas pedagógicas e seus efeitos ou até mesmo olhar seu papel, enquanto docente que lida com diferentes perspectivas de sujeito no contexto escolar.

Para a pesquisa, consideramos interessante questionar onde e como aprenderam essa matemática que utiliza os algoritmos das operações, porém, traz subjacente um tipo de raciocínio que permite a resolução das situações-problema que enfrentam diariamente. Sérgio diz que aprendeu "no dia-a-dia, com as pessoas que eu aprendi a trabalhar de pedreiro. Comecei de ajudante e fui aprendendo até que cheguei neste ponto de ser autônomo".

O pedreiro Oscar, em seu relato, afirma que aprendeu "no curso primário o básico, mas uma grande porcentagem do que a gente usa, aprende com o próprio trabalho. À medida que os problemas vão aparecendo, você vai resolvendo e aprendendo no dia-a-dia da própria construção". Segundo Pompeu e Monteiro (2001), esta postura reflete a adoção da concepção empírica, utilizando-se a matemática para a resolução das situações-problema mais imediatas que perpassam o cotidiano da atividade do pedreiro. O fundamental, nesta perspectiva de acordo com os autores, é dar solução aos problemas práticos enfrentados na labuta diária da profissão.

Questionado a dizer como aprendeu os procedimentos necessários para exercer essa profissão, Oscar relatou que "no começo trabalhou de auxiliar e foi observando como as outras pessoas faziam. Acho que a pessoa tem que ter interesse e com o tempo aprende e aperfeiçoa o que faz, encontrando outras maneiras de fazer os cálculos. Você não pode é ficar parado, tem que ser curioso dentro daquilo que você faz, 
procurando prestar o máximo de atenção para aperfeiçoar e se tornar sempre mais objetivo no trabalho que realiza". Segundo D'Ambrósio (2001) um comportamento que reflete "a aventura da espécie humana na busca de conhecimento e na adoção de procedimentos" (p.17).

"Eu sempre fui muito dedicado ao meu pai que era pedreiro, eu era muito bisbilhoteiro por isso aprendi muitas coisas com ele. Muitas coisas eu também aprendi no dia-adia, mas, sem a matemática da escola seria difícil exercer minha profissão, pois ela ajuda bastante", finaliza Alberto. De acordo com Marques (2000) "os processos de aprendizagem inserem-se inevitavelmente em comunidades comunicativas e públicas em que os homens aprendem uns dos outros e uns com os outros" (p.29).

A matemática precisa ser interpretada como um produto sociocultural-natural de um povo, segundo Rosa Neto (2002, p.7 e 19).

A matemática foi criada e vem sendo desenvolvida pelo homem em função de suas necessidades. (...) A cultura é uma forma de adaptação porque é uma forma de atuação sobre o ambiente que foi construído juntamente com ela.

Para Rosa Neto (2002), existe uma significativa relação entre a matemática e a cultura, ambas como resultado de nossa adaptação em função de nossas necessidades de sobrevivência através dos tempos, representando ambas, um legado empírico, sistemático e científico.

Tendo em vista que os pedreiros participantes da pesquisa consideram que a matemática de que se utilizam, no exercício da profissão, satisfaz suas necessidades profissionais e, pelo fato desta ter sido aprendida em sua formação básica, na labuta diária com outros pedreiros mais experientes, consideramos pertinente perguntar se acreditavam que a matemática da escola poderia melhorar a matemática que utilizam cotidianamente. 
Nas falas demonstraram acreditar que a escola é um local onde de forma organizada e intencional se processa a sistematização dos saberes apreendidos dentro ou fora de seus limites territoriais. Oscar enunciou: "Acredito que a matemática da escola ia melhorar meus cálculos, e eu conseguiria fazer com mais facilidade as coisas partindo sempre da escola. A matemática ensinada na escola é válida e serve de ponto de partida, ajudando naquilo que a gente faz. Embora normalmente a gente sempre opta em fazer do jeito que aprendeu no dia-a-dia". Transparece na fala do pedreiro, segundo Giardinetto (1999) que "O acesso ao conhecimento matemático sistematizado tem sido imprescindível para a própria transformação da vida cotidiana" (p.7).

Através destas enunciações, evidencia-se a presença de um entendimento que encontra respaldo com as reflexões de Giardinetto (1999), ao enfatizar que de fato "o saber escolar supera o modo de pensamento presente no cotidiano a partir de elementos, germens presentes no cotidiano e que são incorporados pelo saber escolar" (p.50). Segundo o autor, "A formação de todo homem vai muito mais além do que aquilo que foi determinado por atividades prático-utilitárias do cotidiano" (p.78).

Para Sérgio, "sem a matemática da escola, até as quatro operações básicas se tornariam difíceis". Isto mostra, segundo Giardinetto (1999) que "o próprio conhecimento que cada indivíduo elabora para a sua vida cotidiana não dá conta de responder às necessidades de sua própria vida cotidiana" (p.7).

Contudo, ao ser questionado sobre como vê a matemática que é ensinada atualmente na escola, Sérgio postulou que ela ajuda as pessoas e é necessária. Enfatizou, porém, que tem dificuldades em opinar com maior profundidade, "Não conheço a matemática da escola. Só fiz até a quarta série e meus filhos ainda são pequenos", conclui.

Segundo Oscar, a matemática escolar de hoje é "muito complexa e muito complicada. São muitas fórmulas e no dia-a-dia você não consegue aplicá-las, tão pouco guardar as fórmulas na memória para fazer os cálculos. Seria importante ensinar a matemática de forma mais prática, mais naquilo que você vai utilizar no teu dia-a-dia em qualquer 
setor. Para o meu trabalho de construção, eu acho que estas fórmulas da escola têm pouca relação com aquilo que eu vou precisar todo dia".

Refletindo sobre a importância de se relacionar o conteúdo matemático com uma situação real, Alberto comenta: "É verdade, como no caso do Teorema de Pitágoras, há anos atrás para tirar o esquadro da casa, a gente usava o próprio esquadro e ficava alinhando até conseguir a metragem certa. Agora, recentemente surgiu para nós o $3 \mathrm{~m} ; 4 \mathrm{~m}$ e $5 \mathrm{~m}$ que também deixa a casa no esquadro. Aprendi na escola que isto é o Teorema de Pitágoras, quer dizer, fazendo a medida $3 \mathrm{~m} ; 4 \mathrm{~m}$, a diagonal com $5 \mathrm{~m}$ coloca tudo no esquadro".

Ao ser instigado sobre a matemática ensinada atualmente na escola Alberto diz que "Ela é muito teórica, deveria trazer mais a parte prática. Trabalhar a prática, não só a teoria, isto seria muito importante para a criança, ajuda no desenvolvimento intelectual. A criança tendo o teórico e o prático ela vai entrar no campo profissional mais esperta", finaliza o pedreiro.

E sua fala, Oscar ainda relata que no exercício de sua profissão "muitas vezes a gente pode resolver determinados cálculos através de outras fórmulas mais simples do que as ensinadas pela escola". Certamente para estes casos, deveríamos nos portar como sugerem Lins e Gimenez (1997), ou seja, "partir do que é mais familiar" (p.10). Com esta postura didática, segundo os autores, o que se aprenderia na escola, não serviria "apenas para a escola" (p.17), pois teriam uma relação direta com os setores de atividade do cotidiano.

Ao serem instigados a falar sobre como gostariam que fosse ensinada a matemática da escola, Alberto prontamente diz: "Com exemplos práticos, buscando aplicações em várias profissões: Comércio, pedreiros, carpinteiros, entre outros. Problemas práticos para não ensinar a matemática só através de resolução de exercícios. Estes problemas de matemática podem fazer o aluno assimilar a teoria e entender tudo melhor, senão fica sem sentido. Eu aprendi o teorema de Pitágoras na escola, mas o professor não mostrou para que ele serve no dia-a-dia, completa o pedreiro. 
As enunciações dos pedreiros mostram, segundo a perspectiva de Lins (1994), em seus estudos sobre o Modelo Teórico dos Campos Semânticos "que o mesmo texto, falado com diferentes justificações, constitui diferentes conhecimentos ${ }^{[8] "}$ (p.29).

Para finalizar a reflexão a que nos propusemos, deixamo-los à vontade para dizerem algo a mais sobre a matemática ensinada na escola e a matemática que utilizam no exercício de sua profissão. Oscar voltou a priorizar em sua fala a importância da matemática escolar, "o básico aprendi na escola e uso hoje na minha profissão. A matemática dos livros que se usa hoje é mais avançada e eu particularmente não utilizo muito no meu trabalho, mas, pode ser que se usa em outras áreas e em outros setores.

A matemática que eu aprendi na escola e a que meus pais aprenderam utiliza bastante a memória. Hoje se usam mais as fórmulas e a calculadora. Eu inclusive nem uso tanto a calculadora, prefiro trabalhar com a memória, embora que a calculadora é bem mais prática. No meu trabalho, em muitas situações preciso definir as coisas com a capacidade da memória, de captar as coisas, finaliza".

Segundo Alberto a matemática da escola "Ajuda muito. Para mim foi muito bom estudar. A experiência que tive com o meu pai foi muito importante, mas, sem a escola não dá. Resolver tudo no grito não funciona. Acho que a matemática da escola tem uma importância muito grande na minha profissão. A matemática da escola me ajudou a evitar muitos erros que eu cometia antes. Todo trabalho feito na construção é realizado com algum tipo de matemática".

Segundo D’Ambrósio (2001), o depoimento do pedreiro mostra que, "Está pelo menos equivocado o educador matemático que não percebe que há muito mais na sua missão de educador do que ensinar a fazer continhas ou a resolver equações e problemas absolutamente artificiais, mesmo que, muitas vezes, tenha a aparência de estar se referindo a fatos reais" (p.46).

Em relação à importância dispensada para a matemática ensinada pela escola, Oscar foi enfático, afirmando que "A gente não pode descartar a matemática da escola 
porque ela ensina os princípios dos cálculos e sem eles tudo fica complicado. Acontece que a matemática da escola se torna complicada por causa de muitas fórmulas e isso, para o pedreiro, traz um certo descontentamento entre os próprios alunos.

Para Rolim,

Pensar o contexto histórico-cultural no processo ensino aprendizagem da Matemática é considerar que o "fazer" envolve mais que regras e técnicas; é reconhecer que enquanto ciência, a Matemática é ela própria, uma construção da humanidade (ROLIM, 2010, p.43).

Com desinteresse o aluno foge da matemática, tem pavor e isso deve ter uma relação com a forma com que ela é ensinada. Acho que não devo falar muito sobre esta questão porque não freqüentei muito à escola. O que eu disse é em função do que acompanhei na vida escolar de meus filhos, tentando ajudá-los em algumas ocasiões e, posso dizer que não tive condições de resolver a maioria das questões e problemas porque é difícil captar as fórmulas que se usam na escola hoje".

A afirmação inicial do pedreiro dá a ideia, segundo Giardinetto (1999) de que, "É preciso compreender que o conhecimento no cotidiano é um conhecimento fragmentário que se manifesta segundo uma lógica conceitual que é própria às exigências de toda a vida cotidiana. Trata-se de uma lógica conceitual adequada aos objetivos prático-utilitários e que responde eficazmente às necessidades do cotidiano" (p.6).

Diante da fala de Oscar, pergunte-lhe se achava que muitas vezes o ensino da matemática se encontrava muito distante de uma situação real, ao que ele concordou dizendo: "Exatamente, se eu olhar para a matemática que uso no meu trabalho e a que está nos livros, 99\% eu não uso no dia-a-dia.

Neste sentido penso que é necessário refletir sobre esta questão e verificar futuramente sobre como tornar a matemática moderna mais aplicada". De acordo com 
Giardinetto (1999), trata-se de compreender a "atividade escolar como mediadora dessa relação de forma a resgatar o papel imprescindível da escola para a formação do indivíduo, superando as interpretações superficiais e imediatas que supervalorizam o saber cotidiano em detrimento da apropriação do saber escolar" (p.12).

Segundo Marques (2000) "A educação em suas várias instâncias, de modo especial na escola, tende à padronização das aprendizagens com vistas à produção do indivíduo modelado pela cultura vigente". Diante dessa constatação do autor, procuramos mostrar que o saber matemático existe e é usado pelas pessoas da comunidade, porém, não de forma única e padronizada. Dentro deste cenário intersubjetivo, acreditamos que somente uma abordagem etno propiciará ao ensino da matemática escolar o debate discursivo sobre os saberes em circulação nas diversas atividades humanas, reconstruindo-se ambos (p.34).

A matemática pode, contudo, se ocupar de conhecimentos e compreensões que não se encaixam nas estruturas institucionalizadas por currículos e programas de pesquisa. Nesse sentido, seria possível colocar em evidência a matemática presente no dia a dia de muitas profissões. Ela é parte integrante da tecnologia, do design e das tomadas de decisão, está nas tabelas, nos diagramas e nos gráficos. Basta folhear um jornal para encontrar muita matemática (SKOVSMOSE, 2014, p. 13-14).

A mediação docente, segundo a perspectiva de Vygotsky (2001) não monopoliza o discurso da sala de aula, porém, transforma-a numa comunidade argumentativa de aprendizagens, onde o papel de ambos é relevante no processo de (re)constituição das aprendizagens. Nesta perspectiva, se alargaria a participação dos alunos na sala de aula e a participação dos setores que compõe a comunidade escolar, criando-se permanentemente um clima de debates cognitivos entre ambos, o que reconstrói e renova as aprendizagens de ambos. 
Nas visitas que fizemos a três lojas que revendem material de construção, chamounos a atenção, tanto o bom atendimento dos funcionários, quanto às manifestações de preocupação dos gerentes, quanto à carência de cursos de capacitação para os pedreiros sobre construção de modo geral e revestimento cerâmico em particular.

Numa das lojas visitadas, à medida que o tema central da investigação chegou aos ouvidos dos dirigentes da empresa, fomos apresentados primeiramente ao engenheiro civil e por ele ao gerente proprietário. No diálogo, ouvimos deles muitas angústias e preocupações. Todas as inquietações eram direcionadas ao tratamento descontextualizado dado à matemática escolar, bem como, a falta de seu domínio pelos pedreiros de modo geral, no exercício de suas profissões.

Em suas falas, relatam reclamações rotineiras de clientes, relacionadas à imprecisão do assentamento cerâmico, especialmente nos casos em que os clientes desejam fazê-lo, assentando a cerâmica na diagonal - 45ำ com a parede. Segundo os depoimentos, nesta região do estado do Paraná, dificilmente se encontra uma parede ou piso no prumo e esquadro, o que também compromete qualquer assentamento cerâmico.

Creditam parte dessa responsabilidade a matemática escolar, a qual segundo eles, tem servido apenas para satisfazer as atividades rotineiras da própria escola. Em suas falas transparece, de acordo com o entendimento de Pompeu e Monteiro (2001) que "vivemos um momento em que a fragmentação do saber limita o entendimento da realidade, [porque] a organização escolar persiste em manter um sistema curricular analítico, cartesiano" (p.19). É fundamental, portanto, que o ensino da matemática escolar contextualize os conteúdos, relacionando-os com as atividades desenvolvidas pelos cidadãos nos diversos setores da atividade humana.

Em sua argumentação crítica, em relação a como a escola ensina atualmente a matemática, o empresário relata que recentemente um senhor - perfurador de poços, veio várias vezes na sua loja pedindo para calcular quantos metros cúbicos teria o poço, que acabara de perfurar. "Da última vez que esteve aqui", diz o empresário, 
"comentou comigo que durante 20 anos havia sido dono de serraria no Estado de Santa Catarina. Perguntei-Ihe então", comenta o gerente proprietário da loja, "se sabia cubicar madeira. Para minha surpresa o perfurador de poços prontamente respondeu": "Com certeza, eu comprava e vendia madeira, precisava saber calcular quantos metros cúbicos tinha cada tora".

"Questionei o perfurador de poços sobre o seguinte" [relata o empresário]: "Caso colocássemos uma tora redonda [circular] dentro desse poço, saberias calcular os metros cúbicos do poço?" 'Sim, aí é fácil”, respondeu o homem e, segundo o empresário, neste momento seu rosto começou a ficar "vermelho" pois agora conseguiu fazer a conexão entre as duas situações.

Durante nossa prosa, tanto o empresário quanto o engenheiro civil, acentuaram a falta de interação existente entre a matemática da comunidade cientifica e a matemática praticada nas diversas atividades humanas, devido as aulas de matemática se restringirem ao âmbito formal.

Situações tais mostram o quanto à matemática escolar está desconexa com as situações reais vividas pelos cidadãos cotidianamente. Contudo, os cidadãos sabem que necessitam desses conhecimentos, porém, apresentam dificuldades para fazer as conexões. Estas observações demonstram, no entendimento de Pompeu e Monteiro (2001) que "Os professores atuais têm pela frente um grande desafio: educados num processo fragmentado, terão de superar os limites que essa formação Ihes impõe e extrapolar as fronteiras de conteúdos vistos de forma parcial e ahistórica" (p.15).

Não se trata de supervalorizar o saber formal ou o informal. A questão que se apresenta, procura refletir sobre possibilidades efetivas de se relacionar a matemática ensinada nas escolas com as matemáticas praticadas nas atividades humanas. Ao fazê-lo reflexivamente, busca-se encontrar pontos convergentes, pois segundo Pompeu e Monteiro (2001), "Se a educação ocorre fundamentalmente numa relação 
"com" o outro, com o mundo, nem o outro nem o mundo podem ser vistos de forma fragmentada" (p.24).

Todas estas perspectivas clarificam o quanto é importante no ensino de matemática, o estabelecimento de vínculos do conhecimento da comunidade com o conhecimento da escola e vice-versa. Esta dinâmica propicia uma (re)construção de ambos os saberes. Em tese, a escola ao trabalhar nesta perspectiva, permite aos alunos compreenderem melhor e sistematicamente o que fazem e porque assim procedem matematicamente.

Segundo o entendimento de Pompeu e Monteiro (2001), "um processo educacional significativo inicia-se com a interação de escola e comunidade" (p.55), cujas relações podem ressignificar o papel da escola como local privilegiado de troca de experiências para se entender melhor o saber que circula no cotidiano.

A adoção de uma prática pedagógica que saia do tecnicismo e centre o olhar na perspectiva de ligar o mundo da vida com o mundo escolar, pode contribuir na minimização do processo de exclusão de um saber matemático crítico reflexivo sobre a realidade. De acordo com D’Ambrósio (1996), significa a adoção de uma postura sócio-interacionista, busca de um novo paradigma educacional em substituição ao já desgastado ensino-aprendizagem, baseado na relação obsoleta de causa-efeito.

Entendemos e compartilhamos com Marques (2000) que nenhum conhecimento pode fechar-se em seu âmbito de ação. Necessita ser socializado, (re) construindo-se por inteiro na e pela ação comunicativa estabelecida entre os sujeitos atores. Com e pelo uso da linguagem, numa perspectiva interativo-dialógica, pode-se propiciar a (re)construção de ambas as aprendizagens, tornando os sujeitos singularizados, não assujeitados.

Que a partir desta reflexão a prática pedagógica em sala de aula possa ser reorientada para o desenvolvimento da plena cidadania dos alunos. Que, segundo Pinheiro e Rosa (2016), os: 
[...] professores de matemática mergulhem na dinâmica cultural dos alunos e utilizem estratégias de ensino e aprendizagem que valorizem a dimensão cultural existente na sala de aula, para que se desenvolva uma educação matemática inclusiva que possa efetivamente contribuir para a transformação social (p. 79).

Um ensino com o enfoque da etnomatemática, acreditamos propiciar aos discentes, condições de interferir na realidade por meio do saber produzido historicamente, colocando o aluno no centro do processo educativo, como sujeito ativo na (re)construção de seu conhecimento. Isto ficou evidenciado nas falas dos pedreiros, pois a partir de sua atividade laboral, criam processos de pensamentos e estratégias próprias, tendo por inspiração seu conhecimento prévio e aprendizagens adquiridas ao longo de sua história de vida.

\section{OBJETIVOS}

4.1 Contribuir a partir da reflexão para que o educador de matemática adote uma postura crítica investigativa em relação ao ensino de matemática, iniciando sua atividade docente através do estabelecimento de vínculos entre a matemática cotidiana e a matemática escolar; 4.2 Contribuir na constituição do professor pesquisador de sua prática, despertando-o a aprender de maneira continuada a ser professor, segundo as atuais necessidades educacionais, transformando a sala de aula num ambiente de troca de saberes, resgatando conhecimentos históricosocialmente construídos pela humanidade; 4.3 Aprofundar o entendimento em relação a etnomatemática, buscando compreender o papel dos diversos contextos culturais na educação matemática, possibilitada pela aproximação entre matemática e realidade.

\section{METODOLOGIA}

Desenvolvemos o trabalho através de momentos distintos, quais sejam: Estudo teórico sobre o tema etnomatemática, conversas com pedreiros e vendedores de lojas 
de material de construção. Investigamos dialogicamente com cada profissional acerca dos conhecimentos matemáticos utilizados na sua atividade. Buscamos refletir pedagogicamente sobre possíveis conexões entre matemática e realidade na possibilidade do estabelecimento de vínculos entre os conhecimentos matemáticos utilizados pelos pedreiros e a matemática escolar.

\section{CONTRIBUIÇÃO ESPERADA}

Espera-se que ensinar matemática em sala de aula através da abordagem etnomatemática ${ }^{[9]}$, permita aos professores e alunos aprenderem sobre a própria diversidade cultural da matemática. Que os resultados desta pesquisa auxiliem no desenvolvimento de uma metodologia que contribua com o ensino da matemática básica, tendo a etnomatemática como suporte para essa compreensão.

Nas palavras de Carneiro um,

[...] ensino da matemática nesta concepção permitirá ao aluno vincular os conceitos trabalhando em classe a sua experiência cotidiana, de acordo com o seu ambiente natural, social e cultural. Não se trata de rejeitar a matemática acadêmica, mas sim incorporar a ela valores que são vivenciados nas experiências em grupo, considerando os vínculos histórico-culturais (CARNEIRO, 2012, p.3).

Através do texto produzido, resultado de leituras e das sessões de estudo, almeja-se pedagogicamente, a união de teoria e prática para a (re)construção do saber sistematizado. Espera-se também que as reflexões decorrentes da leitura do texto permitam um novo olhar sobre a realidade e sobre a educação matemática, na perspectiva da produção do conhecimento a partir da prática cotidiana e do estabelecimento de possíveis conexões entre matemática e realidade. 


\section{REFERÊNCIAS BIBLIOGRÁFICAS}

BREDA, Adriana LIMA, Valderez Marina do Rosário e GUIMARÃES, Gleny Terezinha Duro. A utilização da Etnomatemática nos cursos de formação continuada de professores: implicações das relações de poder saber na produção de subjetividades. Curitiba. Novembro de 2011. Disponível em: http://educere.bruc.com.br/CD2011/pdf/4668_ 2898.pdf. Acessado em: 20/08/2017.

CARNEIRO, K. T. A. Cultura Surda na aprendizagem matemática da sala de recurso do Instituto Felipe Smaldone: uma abordagem etnomatemática. Anais do 4ํㅡㄹ Congresso Brasileiro de Etnomatemática. Belém, PA: ICEm4, 2012.

D'AMBROSIO, Ubiratan. Etnomatemática - elo entre as tradições e a modernidade. Coleção Tendências em Educação Matemática, 1. Belo Horizonte: Autêntica, 2001, $112 p$.

Etnomatemática: Arte ou técnica de explicar e conhecer. Editora Ática, Série Fundamentos, 2. edição, São Paulo, 1993.

. Educação Matemática: da teoria à prática. Editora Papirus (Coleção Perspectivas em Educação Matemática), Campinas - São Paulo, 1996.

DEMO, Pedro. Pesquisa e construção de conhecimento: Metodologia científica no caminho de Habermas. 3.ed. Rio de Janeiro: Tempo Brasileiro, 1996. 125p.

FIORENTINI, Dario. Alguns modos de ver e conceber o ensino da matemática no Brasil. In. Zetetiké. Campinas, São Paulo, ano 3, n.4,p.1-37, 1995.

GIARDINETTO, José Roberto Boettger. Matemática escolar e matemática da vida cotidiana. Coleção polêmicas do nosso tempo, autores associados, Campinas - São Paulo, 1999, 128p.

LOPES, Antônio José. Os saberes das crianças como ponto de partida para o trabalho pedagógico. In: BRASIL. Secretaria de Educação Básica. Diretoria de Apoio 
à Gestão Educacional. Pacto Nacional pela Alfabetização na Idade Certa: Apresentação / Ministério da Educação, Secretaria de Educação Básica, Diretoria de Apoio à Gestão Educacional. - Brasília: MEC, SEB, 2014.

LINS, R. C.; GIMENEZ, J. Perspectivas em Aritmética e Álgebra para o Século XXI. Série Perspectivas em Educação Matemática. SBEM. Campinas: Papirus Editora, 1997, 176p.

LINS, Rômulo Campos. 0 modelo teórico dos campos semânticos: uma análise epistemológica da álgebra e do pensamento algébrico. In: Dynamis, v.1, n.7, p. 29-39, abr/jun, Blumenau, 1994.

MARQUES, Mario Osorio. A aprendizagem na mediação social do aprendido e da docência. ljuí, Editora UNIJUÍ, 2. edição, 2000, 144 p.

Escrever é Preciso: o princípio da pesquisa. ljuí, Editora UNIJUÍ, Coleção educação, 4. edição, 2001, 163p.

MONTEIRO, A.; POMBEU, G. Jr. A matemática e os temas transversais. Editora Moderna, São Paulo, 2001, 160p.

PINHEIRO, R. C.; ROSA, M. Uma perspectiva etnomatemática para o processo de ensino e aprendizagem de alunos Surdos. RPEM, v. 5, n. 9, p. 56-83, 2016.

ROSA NETO, R. Didática da matemática, São Paulo: Ática, 2002.

ROLIM, Carmem Lucia Artioli. Fórmulas de Silêncio: metodologias no processo de ensino da Matemática. In: SANTOS, Jocyléia Santana. ZAMBONI, Ernesta. Potencialidades Investigativas da Educação. Goiânia: Ed. da PUC Goiás, 2010.

SANTOS, Lijecson Souza dos. Contextualização Matemática Em Situação De Ensino E Aprendizagem No Eja. Disponível em: https://editorarealize.com.br/revistas/cintedi/trabalhos/TRABALHO_EV060_MD1_SA 18_ID 492_23102016194610.pdf. 2016. Acesso em 11/11/2017, Hora: 22hrs e 38 min. 
SILVA. Adelmo Carvalho da. et. al. Paradigmas Educacionais: Contribuições para - Ensino de Matemática. In. SILVA, Adelmo Carvalho. et al, Ensinar matemática: Formação, investigação e práticas docentes. Cuiabá, MT: DUFMT, 2012.

SKOVSMOSE, Ole. Um convite à educação matemática crítica. Tradução de Orlando de Andrade Figueiredo. Campinas: Papirus, 2014.

VYGOTSKY, Lev Seminovich. A construção do pensamento e da linguagem. Tradução: Paulo Bezerra, São Paulo, Martins Fontes, 2001, 496p.

8. Conhecimento, nesta perspectiva é entendido como uma crença-afirmação, junto com uma justificação para a crença-afirmação.

9. Neste trabalho utilizado para designar a investigação das concepções, tradições, e práticas matemáticas de um grupo social [pedreiros] e o trabalho pedagógico que pode ser desenvolvido na perspectiva de que o grupo interprete e codifique seu conhecimento; adquira o conhecimento produzido pela matemática acadêmica, utilizando, quando se defrontar com situações contextualizadas, aquele que the parecer mais adequado.

Enviado: Junho, 2019.

Aprovado: Julho, 2019. 